\title{
Stem cell doses in knee osteoarthritis
}

\section{Dosis de células madre en el tratamiento de osteoartritis de rodilla}

\author{
Autores: Samuel E Trujillo ${ }^{1}$, Henao Julieta ${ }^{1}$, Marín Gustavo² ${ }^{2}$ Vargas Camila ${ }^{1}$, Aranzazu Jainer ${ }^{3}$, Murillo Bibiana ${ }^{1}$ Marín Camilo $^{4}$ \\ ${ }^{1}$ Programa de Medicina de la Facultad Ciencias de la Salud. Universidad Tecnológica de Pereira, samueltrujillo@utp.edu.co \\ ${ }^{2}$ Médico Especialista en Ortopedia y Traumatología de Servicios Integrales de Salud Orthotrauma S.A.S, Docente del Programa de Medicina de La Fundación \\ Universitaria de las Américas, guama61@utp.edu.co \\ ${ }^{3}$ Biólogo del Centro de Células Madre y Biotecnología CEMAB, jainer.3105@gmail.com \\ ${ }^{4}$ Residente de la Especialización en Ortopedia de la Fundación Universitaria Ciencias de la Salud, bolijangueo31@hotmail.com
}

Fecha de recepción: Marzo 15 de 2019

Fecha de corrección Noviembre 10 de 2019

Fecha de aceptación Diciembre 12 de 2019

Fecha de publicación Diciembre 15 de 2019

\section{Resumen}

La osteoartritis (OA) es una enfermedad degenerativa,cuyo tratamiento convencional incluye medicamentos, fisioterapia o prótesis. Las células madre con Plasma Rico en Plaquetas y factores de crecimiento son una opción que promete controlar los síntomas, mejorar la función y regenerar el cartílago; sin embargo, no se han especificado muchos detalles del tratamiento, como el tipo y la cantidad de células madre que se deben aplicar para obtener mejores resultados. En este estudio buscamos comparar la efectividad, la seguridad y los costos

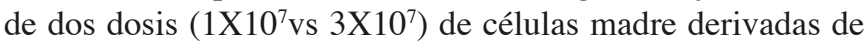
tejido adiposo (ADSC), aplicadas por vía intraarticular.

Diez pacientes, con OA de rodilla grados II y III, fueron aleatorizados para recibir $10(\mathrm{n}=5)$ o 30 millones $(\mathrm{n}=5)$ de ADSC autólogos. Al inicio y 6 a 10 meses después de la inyección, se evaluaron de acuerdo con los criterios clínicos (evaluación médica, escala WOMAC, calidad de vida) y paraclínicos (artroscopia, resonancia, biopsia).

En términos de efectividad y seguridad no se observaron diferencias entre los dos grupos de dosificación, ya que todos los pacientes tuvieron una mejoría de acuerdo con los criterios médicos y la escala WOMAC $(\mathrm{P}=0,001)$; en el control artroscópico, 7 pacientes tuvieron una respuesta "buena / muy buena", 1 "neutral" y 2 abandonaron el control; Las biopsias confirman la regeneración articular, aunque no hubo diferencias en las resonancias magnéticas anteriores y posteriores.

En la osteoartritis de rodilla, la aplicación de 10 o 30 millones de ADSC fue igualmente efectiva y segura; sin embargo, el protocolo con 10 millones de células no requiere expansión in vitro, requiere menos tiempo, es más simple y tiene un costo menor. Este estudio muestra una buena razón para realizar ensayos clínicos aleatorios para obtener evidencia de mayor calidad.

Palabras clave: factores de crecimiento, osteoartritis, calidad de vida, medicina regenerativa, células madre.

\section{Stem cell doses in knee osteoarthritis}

\section{Abstract}

Osteoarthritis (OA) is a degenerative disease where conventional treatment includes drugs, physiotherapy, or prostheses. Stem cells and growth factors are a promising option in controlling symptoms, functional improvement and cartilage regeneration; however, many treatment details have not been specified, such as type and number of stem cells that should be applied to obtain optimal results. In this study we sought to compare effectiveness, safety and costs of two doses $\left(1 \times 10^{7}\right.$ vs $\left.3 \times 10^{7}\right)$ of adipose tissue derived stem cells (ADSC), applied intra-articularly.

Ten patients, with knee OA grades II and III, were randomized to receive $10(n=5)$ or 30 million $(n=5)$ of autologous ADSCs. At baseline and 6 to 10 months after injection, they were evaluated according to clinical (medical evaluation, WOMAC scale, quality of life) and paraclinical criteria (arthroscopy, resonance, biopsy).

In terms of effectiveness and safety there were no differences observed among the two dosage groups since all patients had improvement according to medical criteria and the WOMAC scale $(\mathrm{P}=0,001)$; in the arthroscopic control, 7 patients had "good/very good" response, 1 "neutral" and 2 forwent control; biopsies confirm joint regeneration, although there were no differences in the before and after magnetic resonances.

In knee osteoarthritis, the application of 10 or 30 million ADSCs was equally effective and safe; however, the protocol with 10 million cells does not require in vitro expansion, requires less time, is simpler and has a lower cost. This study shows good reason to undertake randomized clinical trials to gain higher quality evidence.

Key words: growth factors, osteoarthritis, quality of life, regenerative medicine, stem cells. 


\section{Introduction}

As the life expectancy of the population increases, diseases related to aging increase and many of which are becoming public health problems. This is the case of osteoarthritis (OA), a disease characterized by degeneration of the articular cartilage, alteration of the properties of the subchondral bone, inflammation of the synovial membrane, ligament degeneration and hypertrophy of the joint capsule $(1,2)$. OA is the most common arthritis among adults and causes significant deterioration of the quality of life in people over the age of 65 , especially for joint pain and disability (3). The main factors associated with OA are age, obesity, female gender and the genetic component (4).

The function of normal joint tissue depends on the relationship between the synovial membrane, the articular cartilage and the subchondral bone. Articular cartilage receives its nutrition by diffusing nutrients from the synovial fluid, through the extracellular matrix, whose components give the mechanical properties to the cartilage and facilitate joint lubrication (5). With natural tissue regeneration, growth inducers are released by the platelets, whose function is to stimulate tissue proliferation from the stem cells resident in the affected tissue; these factors also inhibit apoptosis and fibrosis, so that in most cases they induce normal tissue regeneration (6). Among the growth factors that have important chondrogenic activity, we can mention transforming growth factor-beta (TGF-beta), fibroblast growth factor (FGF) and insulin-like growth factor (IGF) (7).

The central pathological characteristic of OA is the loss of articular cartilage and the involvement of other joint components. It is divided into two categories: primary (to which efforts are directed, since it is the one with the highest incidence) results from biomechanical abnormalities or genetic predisposition; secondary is associated with metabolic, systemic or traumatic disorders, which alter the distribution of loads on the affected joint (8). Articular cartilage has poor repair capacity, mainly due to lack of vascularization and shortage of stem cells, so a focal lesion of the cartilage can be extended without there being any way to control it by conventional methods; additionally, it is possible that the little tissue that can regenerate does not have the same biochemical and biomechanical properties of the native cartilage $(7,9)$.

These changes can be evidenced radiologically and they are based on the classification of knee osteoarthritis according to the scale of Kellgren and Lawrence: grade 1, doubtful narrowing of the joint space and possible osteophytosis; mild grade 2, possible narrowing of the joint space and osteophytosis; moderate grade 3 , narrowing of the joint space and multiple moderate osteophytosis, mild sclerosis and possible deformity of the ends of the bones; severe grade 4, marked narrowing of the joint space, abundant osteophytosis, severe sclerosis and deformity of the ends of the bones, in addition to the clinical manifestation of knee pain, bone crepitus to active movements and morning stiffness.

The conventional treatment of $\mathrm{OA}$, based on symptomatic medication and physiotherapy, shows only modest clinical benefits, therefore a good number of patients end up as candidates for joint replacement. Even so, 15 to $20 \%$ of patients are dissatisfied with surgery due to functional limitation, and 20 to $30 \%$ continue with pain, which presents a serious concern since pain is the chief complaint of patients requesting surgery (3); therefore, all attention must be paid to the search for new alternatives for OA treatment.

Some cartilage repair techniques, such as abrasive chondroplasty, subchondral perforation and microfractures, seek to stimulate the migration of stem cells from the bone marrow to the damaged area and their subsequent differentiation into chondrocytes. Unfortunately, the tissue regenerated in this way does not possess the biological or biomechanical properties of the native cartilage, so it quickly degenerates. Regenerative medicine now emerges as a new therapeutic paradigm with the potential to regenerate damaged tissues and cure conditions that have been difficult to manage or have low level of response to traditional treatments (9).

Stem cells can be isolated from any tissue of the body and at any time of life, but among the different types of stem cells there are sufficiently important differences in terms of the requirements for obtaining them, yield in number of cells per gram of tissue, conditions of culture, vitality and potential for differentiation, among others $(10,11)$. Stem cells derived from adipose tissue (ADSC) have turned out to be an attractive alternative for clinical use, not only for their relative ease of recovery, isolation and in vitro expansion, but because, compared to other cells, they have greater capacity for proliferation, in the laboratory they can be subjected to more passages without showing signs of senescence, maintaining their potential for differentiation and a stable phenotype, even after long periods of cultivation; they seem to be better for allogeneic transplantation than those of bone marrow. Finally, the patient's age has less effect on their vitality and this is still shown in elderly patients with osteoporosis $(12,13)$. In the specific case of the treatment of OA, ADSCs have shown high chondrogenic potential and low tendency towards osteogenic differentiation, with cartilage production of normal macroscopic characteristics and good integration with the subchondral bone $(9,14)$. All these well-documented biological properties explain the rapid increase in preclinical and clinical studies with ADSCs in the treatment of a wide range of diseases, among which knee OA has received special attention. Indeed, several studies report that the injection of intraarticular stem cells result in clear recovery of cartilage and clinical parameters (pain and functional limitation), imaging, arthroscopy and quality of life (15-17); the addition of growth factors is done to stimulate cell proliferation and differentiation and generate an adequate extracellular matrix 
to stimulate cartilage development (9). However, it should also be noted that concerns still persist regarding the source and manipulation of the stem cells to be used, the pharmaceutical forms to be administered, the administration routes and the optimal dosage regimen; on the other hand, some experts consider that, even though there is good confidence in safety, it is necessary to accumulate more evidence regarding the effectiveness of its application in humans (18).

In this trial, we proposed to evaluate the effectiveness, safety, and costs of two ADSC dose regimens administered intraarticularly in patients with knee OA.

\section{Materials and methods}

Legal aspects. This pilot study was approved from a technical and scientific point of view by the respective academic instances of the Technological University of Pereira, and from the ethical point of view of the Bioethics Committee of the same university. Informed consent form was filled out and signed in accordance with Resolution 008430 of 1993 of the Ministry of Health of Colombia, in the category of "investigation with risk greater than the minimum".

Patients and medical assessment. The study included 10 patients over 40 years of age, both sexes, assessed by the specialist in Orthopedics and Traumatology, with OA grade II or III diagnosis (Kellgren-Lawrence classification), confirmed according to the criteria of the American College of Rheumatology (Altman 1986) by means of radiological, arthroscopic and magnetic resonance studies. The exclusion criteria were cerebral trauma, autoimmune disease, cognitive deficit or severe psychiatric illness (dementia or psychosis) that compromised the ability to sign the consent, hemorrhagic syndrome or coagulation disorder, active infection, immunological disorder, current consumption of NSAIDs or glucocorticoids, pregnancy or lactation.

Process. Each volunteer filled out the information gathering document of the study and the following instruments were applied: i) The WOMAC scale (Western Ontario and Mc Master Universities Osteoarthritis Index), which is validated to determine the clinical response in patients with knee OA (19). This scale has been designed to measure symptomatology and physical disability of patients with knee osteoarthrosis, among others; contains 24 items, each with five levels, grouped into three domains: pain ( $0-20$ points), rigidity ( $0-8$ points) and functional disability (0-68). To present the results the scores of the three domains are added together and the total is multiplied by 100/96; thus, a value between 0 (the best) and 100 (the worst) is obtained. ii) The World Health Organization Quality of Life instrument, abbreviated version (WHOQoL-BREF), which estimates the quality of life in four areas: health and physical, psychological, social and environmental conditions (20).

Patients were randomly assigned to the application of 10 million stem cells directly isolated from adipose tissue, or 30 million of the same cells, cultured for two weeks. Subsequently, conventional magnetic resonances for knee OA were requested, without special recommendations, because the purpose was to determine its usefulness in this pathology. Finally, under spinal or general anesthesia, laparoscopies were performed and biopsies taken.

Obtaining the fat. In sterile conditions and in the same surgical act of arthroscopy, by means of a small incision in the abdominal wall, the doctor obtained by mini liposuction about $100 \mathrm{cc}$ of adipose tissue. The sample was immediately transferred to the CeMaB/UTP Regenerative Medicine Laboratory.

Stem cells isolation and preparation. The lipoaspirate sample was subjected to the process of isolation and preparation of stem cells under sterile conditions with the Unistation (Neogenesis) and the closed system Unistation Adipose Stem Cell Isolation Device, by the procedure described by Yoshimura et al (21), which is endorsed by the International Society for Cell Therapy: the lipoaspirate sample is washed to remove erythrocytes and then $0.1 \%$ type I collagenase (Sigma, USA) is added and incubated at $37^{\circ} \mathrm{C}$ in the Unistation equipment with constant agitation for $30 \mathrm{~min}$. The bottom layer is removed, transferred to a new $50 \mathrm{~mL}$ syringe containing HBSS (Gibco, USA) and centrifuged at Unistation at 1500 rpm for $10 \mathrm{~min}$. After the neutralization of the enzymes, the released elements are separated from the mature adipocytes by differential centrifugation; the mixture is centrifuged at $1,500 \mathrm{rpm}$ for $10 \mathrm{~min}$ to then remove the supernatant (22). To the patients whom 10 million ADSCs were applied, the pellet of the stromal vascular fraction containing the concentrated stem cells was reconstituted in a volume of $6 \mathrm{ml}$ of plasma rich in growth factors, while the patients who were applied 30 million ADSC, these cells were first cultivated until achieving the required concentration, at approximately two weeks.

Obtaining autologous platelet growth factors. Platelet rich plasma (PRP) was obtained using the Neogenesis PRP kit in the Unistation kit, for which $20 \mathrm{ml}$ of blood was taken from the patient, with sodium citrate as an anticoagulant, in a syringe of the PRP Neogenesis kit, and centrifuged to $1700 \mathrm{~g}$ for 5 min; subsequently, under sterile conditions and closed form, the platelet-rich plasma layer was obtained.

Application of stem cells with autologous platelet growth factors. Once ready, the cells were injected in the next two hours into the affected joint, by the orthopedist; no premedication was used and no other substances were added to the injection. This procedure requires a 72-hour disability at home, during which time the patient was closely monitored by the health team. An indication was given not to consume NSAIDs for up to one week after the procedure; if post-infiltration pain treatment was required, the use of acetaminophen was indicated. A formal rehabilitation program was not recommended.

Between the sixth and the tenth month after infiltration, a new magnetic resonance was requested, and the medical team 
performed the clinical evaluation of the patient (WOMAC scale and the WHOQoL-BREF) and the second arthroscopic view, with a final biopsy. The radiologists and pathologists who interpreted the images and biopsies were blinded with respect to the doses of applied stem cells.

Magnetic resonances. They were practiced and read by the radiologist without special guidelines, as if they were typical patients of medical practice. Therefore, comparisons of the pre- and post-operative charts were made only by classifying the type of patella and measuring the thickness of the patellar cartilage at the level of the internal and external facets.

Arthroscopy. Three doctors from the surgical team of the group separately rated the response of the cartilage in the area of greatest commitment, as "very positive" (important changes in the entire cartilage, with good integration to the adjacent normal joint surface and normal appearance), "positive" (new cartilaginous tissue is found, partially covering the degenerated cartilage), "neutral" (the changes are uncertain) or "negative" (there was progression in the degeneration of the cartilage) (23). If there were discrepancies between the evaluators, the decision was adopted by majority.

Biopsies. They were taken during the arthroscopic procedures, before and after the application of the stem cells, in areas that the orthopedist considered representative of the local histopathological condition. The plates were analyzed by two medical histopathologists.

Finally, the costs of each of the two treatment branches were established, with the purpose of implementing the treatment protocol with the best benefit / safety / cost ratio of moderate to severe osteoarthritis of the knee.

Statistics. Due to the small size of the sample non-parametric tests were used in all evaluations. For the differences between the two treatment groups, the Mann-Whitney test was used for continuous variables. Changes in quantitative variables were evaluated with the Wilcoxon rank test; the qualitative variables were evaluated by Fisher's test.

\section{Results}

Table 1. Demographic and comorbidity characteristics of patients classified according to the doses of prescribed stem cells.

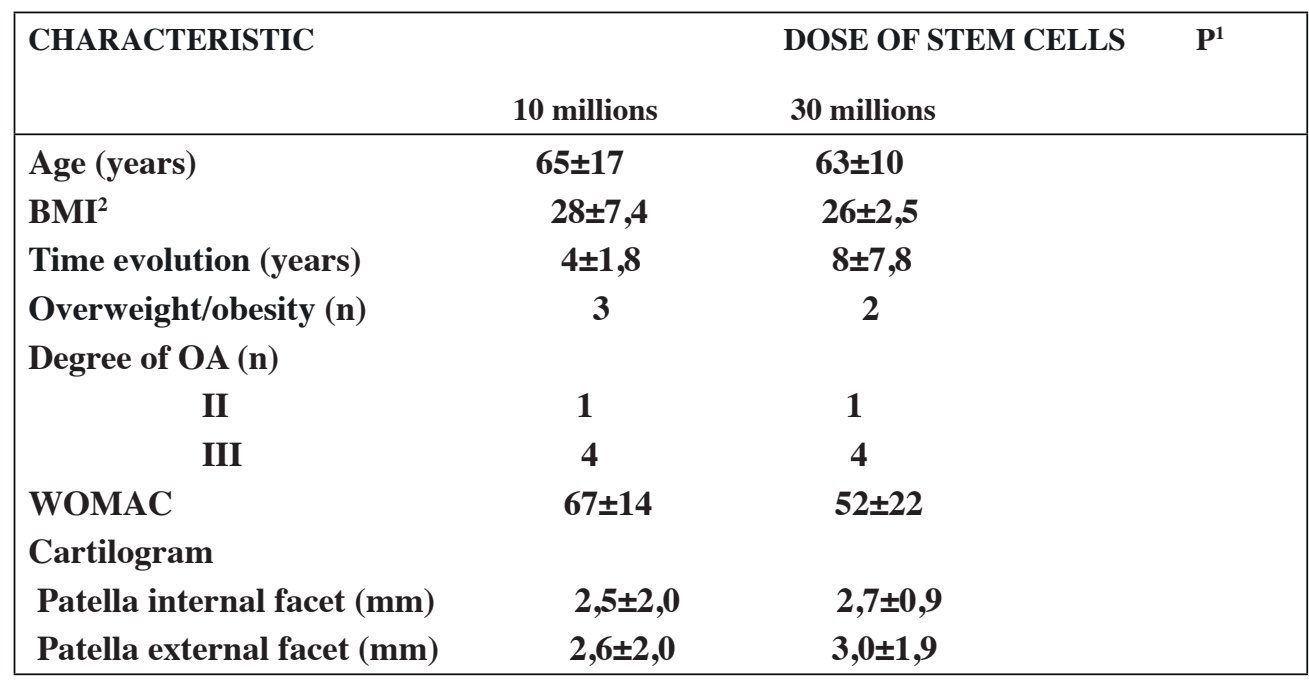

${ }^{1}$ : none of the differences is significant.

2: body mass index. 
Table 2. Results of the WOMAC scale.

\begin{tabular}{|ccc|}
\hline PATIENT & INITIAL WOMAC & FINAL WOMAC \\
STEM CELLS DOSE & & \\
\hline Ten millions of stem cells & & \\
1 & 46,88 & 21,88 \\
2 & 80,21 & 46,35 \\
3 & 67,71 & 58,33 \\
4 & 59,38 & 54,69 \\
5 & 81,25 & 32,29 \\
Thirty millions of stem cells & & \\
6 & 68,75 & 46,88 \\
7 & 37,50 & 34,90 \\
8 & 55,21 & 29,69 \\
9 & 75,00 & 37,50 \\
10 & 20,83 & 10,42 \\
\hline
\end{tabular}

${ }^{1}$ : the differences are significant (Wilcoxon test, $\mathrm{P}=0.005$ ).

Nine women and one man participated in the study, with an average age of $64 \pm 13$ years (range 40 to 82 years of age), all of them received comedication and their predominant comorbidity was hypertension $(n=6)$ and overweight/obesity $(n=5)$. The evolution time of osteoarthritis was 5,9 5,7 years (range of 1,0 to 20 years). The data of the baseline conditions of the patients are shown in table 1. Table 2 shows the WOMAC scale scores for each of the patients, before and 10 months after the application of the stem cells. In the complete group of 10 patients the scores decreased significantly from $59 \pm 20$ to $37 \pm 15$ points $(\mathrm{P}=0,005)$, which is equivalent to a reduction of $37 \%$ in the total score of the WOMAC scale, with pain being the symptom that responded best (reduction of $41 \%$ ), followed by functional disability $(36,5 \%)$ and rigidity $(28,6 \%)$. There were no differences in the WOMAC scale between the two treatment groups (10 million, reduction of $36 \%$ vs 30 million, reduction of $38 \%$ ).

Table 3. Results of the WHOQoL-BREF of the World Health Organization.

\begin{tabular}{|c|c|c|}
\hline DOMAIN & INITIAL & 4-6 MONTHS AFTER \\
\hline Perception of quality of life ${ }^{1}$ & $3.9 \pm 0.8$ & $4.0 \pm 0.9$ \\
\hline Satisfaction with health ${ }^{2}$ & $3.9 \pm 0.8$ & $4.0 \pm 0.9$ \\
\hline Physical health $\left(\%\right.$, quartile $^{3}$ & $59 \pm 18$ (average) & $64 \pm 20$ (average) \\
\hline Psychological health $(\%, \text { quartile })^{3}$ & $73 \pm 20$ (average) & $76 \pm 20$ (average) \\
\hline Social relationships $(\%, \text { quartile })^{3}$ & $83 \pm 11$ (high) & $86 \pm 8$ (high) \\
\hline Environnemental conditions (\%, quartile $)^{3}$ & $73 \pm 16$ (average) & $76 \pm 15$ (average) \\
\hline
\end{tabular}

1: scale from 1 (very bad) to 5 (very good).

2: scale from 1 (very dissatisfied) to 5 (very satisfied).

3: scale from 1 to 100, with a degree of satisfaction low (below the first quartile), medium (between the first and third quartile) and high (above the third quartile).

4: none of the differences is significant. 
There were no changes in the perception of quality of life according to the WHOQoL-BREF of the World Health Organization, applied to the study entry and between 6 and 10 months after the administration of the stem cells (table 3 ); no changes were found within each treatment subgroup (data not shown).

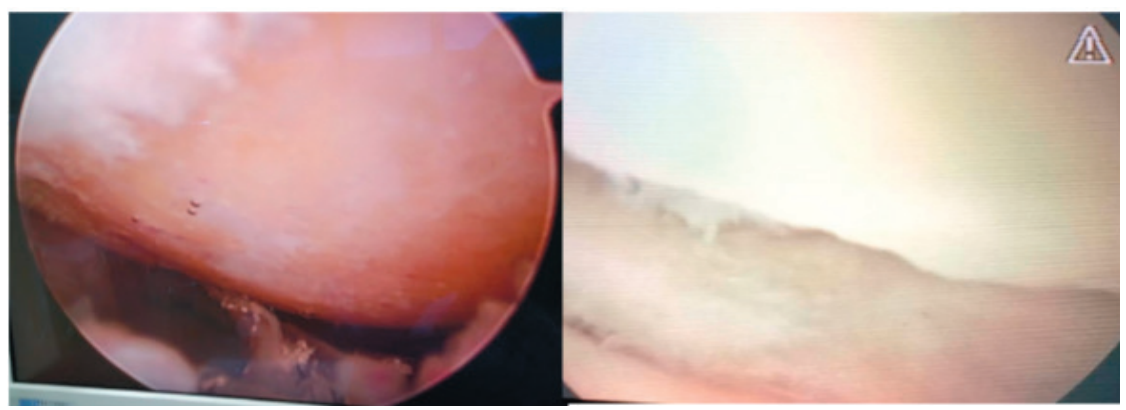

Fig $1 \mathrm{~A}$

Fig 1B

Figure 1. Arthroscopic knee photographs, taken before (A)and after (B) stem cells aplication. (A): lateral knee condyle arthroscopy; a denuded area is seen without joint cartilage. (B): arthroscopy of the same knee, in which articular cartilage regeneration is appreciated, good integration to the adjacent articular surface and normal appearance.

Arthroscopies (figures 1A and 1B). On the second look, about 10 months after the treatment, the following is the evaluation of the arthroscopic results, by the three doctors of the surgical team: result "good/very good" 7 patients, result "neutral" 1 patient, there were no negative results and 2 patients did not undergo control arthroscopy, although they reported clinical improvement.

Magnetic resonances. There were no significant differences in the thickness of the patellar cartilage, at the level of the internal and external facets, in the cartilages taken at baseline and on average 7.4 months after the application of the stem cells (range 6 to 9 months); there were also no differences between patients who received 10 or 30 million cells.

\begin{tabular}{|c|c|c|}
\hline Fig 2A & Fig 2B \\
\hline & & \\
\hline & & \\
\hline
\end{tabular}

Figure 2. Microphotographs of osteoarticular knee tissue biopsies taken before (A) and after (B) stem cells aplication (100X magnification, hematoxylin/eosin stain). (A) trabecular bone tissue, areas of dense irregular connective tissue, adipose tissue (yellow bone marrow) and a sparse area of hyaline cartilage with chondrocytes cells and less affinity for hematoxylin (poor basophilia); sparse and eosinophilic territorial matrix; eosinophilic inter-territorial matrix (B): hyaline cartilage with chondroblasts and chondrocytes cells, abundant territorial matrix, with good hematoxylin affinity (marked basophil); different isogenic groups of different sizes are observed.

Biopsies. As illustrated in figure $2 \mathrm{~A}$, in the plates taken before the application of the stem cells the typical pattern of chondral degeneration prevails, while the images of the biopsies taken 10 months later (figure $2 \mathrm{~B}$ ) show unequivocal signs of regeneration, with hyaline cartilage, chondroblasts and isogenic groups of different sizes.

Security and adverse events. There were no serious adverse events. The only undesirable symptoms reported by all patients were pain and mild-moderate edema in the intervened knee, which were treated ambulatory with rest, local cold and acetaminophen, 
lasted a few days and resolved without sequelae.

Costs. The protocol with 10 million stem cells has the same effectiveness and safety as the $\mathbf{3 0}$ million, but it is logistically more convenient, requires less time, and is simpler and cheaper.

\section{Discussion}

OA is pathology of high prevalence, which exposes the patient to a life with pain and functional limitation, and with serious social, labor and economic consequences. The therapeutic alternatives based on medications and physiotherapy have modest results and do not modify the natural course of the disease, so that for many patients, joint replacement ends up being their only option. In these circumstances, the search for innovative therapies that overcome the precarious results of current treatments at affordable costs is justified (24).

The intra-articular application of stem cells and growth factors emerges as a promising option, since it is the only known alternative with regenerative properties of cartilage and other tissues involved in OA. This is indicated by the numerous reports of successful results, in which it is shown that regenerative medicine is safe, reduces pain and improves joint function (8).

However, there are also reports of lack of benefit, which has led some authors to consider that the evidence of effectiveness is still limited (25). Among the factors that have probably influenced the results of the clinical trials some have not been consistent, have been the heterogeneity of the studies in terms of the type and quality of the stem cells used, its support or not with growth factors, the route of administration and the amounts applied.

With the purpose of contributing to the clarification of some doubts that still persist, in this pilot study we decided to look for a type and a dose of stem cells that would meet the safety, effectiveness and cost profile, which would allow us to propose a protocol for the treatment of OA of knee, based on regenerative medicine.

The most remarkable finding of this research is that the intraarticular application of autologous ADSCs was safe and significantly beneficial in patients with knee OA. Apart from slight pain and inflammation, there were no significant adverse events that could be associated with surgical procedures (liposuction and intra-articular injection), or the action of stem cells and growth factors. On the other hand, the clinical benefit judged by the significant changes in the WOMAC scale (table 3 ) is confirmed by arthroscopic evaluations, which show significant growth of the articular cartilage (figures $1 \mathrm{~A}$ and $1 \mathrm{~B})$, and with the histological findings that show regeneration tissue (figures $2 \mathrm{~A}$ and $2 \mathrm{~B}$ ). It is known that washing and debridement performed by the surgeon during arthroscopy causes some clinical improvement, but this is temporary and is not associated with tissue regeneration $(26,27)$; for this reason, the benefit of the patients is attributed to the regenerative treatment applied.

Although the comparison with previous studies is difficult due to large differences between them, these results coincide with dozens of clinical trials, systematic reviews and metaanalyzes, in which the effectiveness and safety of the stem cells and the growth factors for the treatment of knee OA is confirmed $(15,17)$. It should be noted that, although it has been demonstrated on different occasions that the age and comorbidity of the donor negatively impact the vitality of their stem cells (28), our results coincide with other studies done with ADSC, in which they do not find a correlation between the capacity for differentiation chondrogenic of said cells and the age and comorbidity of the donor (12).On the other hand, the follow-up time of the patients in our study is relatively short, but it should be mentioned that in similar cases benefits have been reported in follow-ups of 2 to 5 years after the application of stem cells; Even in some studies, the improvement in the WOMAC scale has become significant at a longer time (2 years), which suggests that our patients could continue to improve over time $(4,17)$.

The second result of interest is that no differences were found, in terms of safety and effectiveness, between those who received 10 or 30 million stem cells, although this finding should be taken with caution, because the size of our sample was small and the cutting of the evaluation relatively short.

However, the differences between the two doses are clinically relevant, since in order to obtain 30 million ADSCs it is necessary to expand them ex vivo, with everything that involves the cultivation in costs, handling and processing time, risk of contamination or change of properties in biological cells (29). To have 10 million cells, on the other hand, the entire procedure (obtaining fat tissue, isolation of cells and intra-articular application) can be done in a single session, which takes around two hours. Even so, the autologous application requires a previous intervention of liposuction to obtain the cells, hence the supply of stem cells is migrating towards allogenic sources (for example, umbilical cord), which seem to have a similar safety profile to autologous ones, with the advantage that can be produced in a standardized way, conserved to scale and dispensed in a timely manner, which reduces product variability and costs $(1,31)$.

The lack of changes in the quality of life qualification of our patients is not surprising, since the WHOQoL-BREF and other questionnaires, such as the SF-36 and the SF-18, that make a multidimensional assessment of the quality of life (area physical, psychological, social and environmental), applied in patients with osteoarthritis subjected to different treatments, give questionable results or only valid for some domains of the questionnaire $(13,31)$. The explanation seems 
to be that these patients often suffer from other chronic diseases, are polymedicated, have psychosocial deprivation and difficulties in accessing health services, which are not related to joint dysfunction and pain, and are not affected during the regenerative treatment (30). For these reasons, the questionnaires focused on the particular conditions of the patient with OA, such as the WOMAC, which was developed specifically for patients with lower limb joint damage, has become more reliable and has become a valuable tool in the evaluation of functional level and of pain in the patient with knee OA (31).

The fact that no differences were found in the magnetic resonances made before and after the application of the stem cells may be due to the fact that only two anatomical points of the patella were measured and compared since the average follow-up time was only 7,4 months. Although in this short follow-up period there was no additional chondral degeneration, most studies that report significant improvements in the magnetic resonances show that the responses are not uniform at all the points measured, using image qualification criteria that include different structures of the knee (such as the WORMS or 2D MOCART scales), or have longer followup periods $(4,13,23,31)$. This result allows us to question the value of the magnetic resonances that are made in conventional clinical practice, for the diagnosis and monitoring of knee osteoarthritis.

It is necessary to highlight some limitations of this study. First, the size of the sample limits the power of the investigation; indeed, large controlled studies are required to get more conclusive data on the benefits, not only clinical but structural cartilage. Second, the observation period was short to draw more definitive conclusions, so it would be desirable to have longer-term information, although in any case the response of the patients was significant enough to overcome any other treatment they received to date. Third, the debridement that is made during arthroscopy and the simultaneous use of plateletrich plasma will not allow to specify the role of ADSCs in the benefit of the patient. Fourth, one fifth of our patients (2/10) did not accept control arthroscopy, although with the remaining eight patients we demonstrated that there is a correspondence between clinical improvement and arthroscopic improvement. Finally, some data comes from what was declared by the patient, with the consequent reservations of credibility.

The purpose of this pilot study has been to contribute to establishing a dose of stem cells with a good benefit / risk / cost ratio, as a contribution to medical practice and to the design of randomized and controlled clinical trials, with greater evidence power.

\section{Acknowledgments:}

The members of the working group, we express our gratitude to: Department of Science, Technology and Innovation
(COLCIENCIAS) Bogotá, Colombia, the Technological University of Pereira (UTP), Pereira, Colombia, Integral Health Services Ortotrauma S.A.S. and the Stem Cell and Biotechnology Center (CeMaB), Pereira Colombia, for the resources and support for the realization of this research.

Conflict of interests: The authors declare that we have no conflict of interest.

\section{References}

1. De Bari C, Roelofs AJ. Stem cell-based therapeutic strategies for cartilage defects and osteoarthritis. Curr Opin Pharmacol. 2018 3;40:74-80. doi:10.1016/j. coph.2018.03.009.

2. Krajewska-Włodarczyk M, Owczarczyk-Saczonek A, Placek W, Osowski A, Wojtkiewicz J. Articular Cartilage Aging-Potential Regenerative Capacities of Cell Manipulation and Stem Cell Therapy. Int J Mol Sci. 2018. doi: 10.3390/ijms19020623.

3. Nyvang J, Hedström M, Gleissman SA. It's not just a knee, but a whole life: A qualitative descriptive study on patients' experiences of living with knee osteoarthritis and their expectations for knee arthroplasty. Int J Qual Stud Health Well-being. 2016;11:30193. doi: 10.3402/qhw.v11.30193.

4. Spasovski D, Spasovski V, Baščarević Z, Stojiljković M, Vreća M, Anđelković M, et al. Intra-articular injection of autologous adipose-derived mesenchymal stem cells in the treatment of knee osteoarthritis. J Gene Med. 2018;20(1). doi: 10.1002/jgm.3002.

5. Athanasiou KA, Responte DJ, Brown WE, $\mathrm{Hu}$ JC. Harnessing biomechanics to develop cartilage regeneration strategies. J Biomech Eng 2015;137(2):020901.

6. Kokai LE, Marra K, Rubin JP. Adipose stem cells: biology and clinical applications for tissue repair and regeneration. Transl Res.2014;163:399-408.

7. Bastos R, Mathias M, Andrade R, Bastos R, Balduino $A$, Schott V, et al. Intra-articular injections of expanded mesenchymal stem cells with and without addition of platelet-rich plasma are safe and effective for knee osteoarthritis. Knee Surg Sports Traumatol Arthrosc. 2018. doi: 10.1007/s00167-018-4883-9.

8. Zhao L, Kaye AD, Abd-Elsayed A. Stem Cells for the Treatment of Knee Osteoarthritis: A Comprehensive Review. Pain Physician. 2018;21(3):229-242. PubMed PMID: 29871367. 
9. Fisher JN, Tessaro I, Bertocco T, Peretti GM, Mangiavini L. The Application of Stem Cells from Different Tissues to Cartilage Repair. Stem Cells Int. 2017;2017:2761678. doi: 10.1155/2017/2761678.

10. Beeravolu N, Khan I, McKee C, Dinda S, Thibodeau $\mathrm{B}$, Wilson $\mathrm{G}$, et al. Isolation and comparative analysis of potential stem/progenitor cells from different regions of human umbilical cord. Stem Cell Res. 2016;16(3):696-711. doi: 10.1016/j.scr.2016.04.010.

11. Lunyak VV, Amaro-Ortiz A, Gaur M. Mesenchymal Stem Cells Secretory Responses: Senescence Messaging Secretome and Immunomodulation Perspective. Front Genet. 2017;8:220. doi: 10.3389/ fgene.2017.00220.

12. Gu X, Li C, Yin F, Yang G. Adipose-derived stem cells in articular cartilage regeneration: current concepts and optimization strategies. Histol Histopathol. 2017:11955. doi: 10.14670/HH-11-955.

13. Song Y, Du H, Dai C, Zhang L, Li S, Hunter DJ, Lu L, Bao C. Human adipose-derived mesenchymal stem cells for osteoarthritis: a pilot study with longterm follow-up and repeated injections. Regen Med. 2018;13(3):295-307. doi: 10.2217/rme-2017-0152.

14. Dubey NK,MishraVK, Dubey R,Syed-Abdul S, Wang JR, Wang PD, et al. Combating Osteoarthritis through Stem Cell Therapies by Rejuvenating Cartilage: A Review. Stem Cells Int. 2018;2018:5421019. doi: 10.1155/2018/5421019.

15. Filardo G, Perdisa F, Roffi A, Marcacci M, Kon E. Stem cells in articular cartilage regeneration. J Orthop Surg Res. 2016;11:42. doi: 10.1186/s13018016-0378-x.

16. Cianca JC, Jayaram P. Musculoskeletal Injuries and Regenerative Medicine in the Elderly Patient. Phys Med Rehabil Clin N Am. 2017;28(4):777-794. doi: 10.1016/j.pmr.2017.06.010.

17. Yubo M, Yanyan L, Li L, Tao S, Bo L, Lin C. Clinical efficacy and safety of mesenchymal stem cell transplantation for osteoarthritis treatment: A meta-analysis. PLoS One. 2017;12(4):e0175449. doi:10.1371/journal.pone.0175449.

18. Xing D, Wang Q, Yang Z, Hou Y, Zhang W, Chen $\mathrm{Y}$, et al. Mesenchymal stem cells injections for knee osteoarthritis: a systematic overview. Rheumatol Int. 2017. doi: 10.1007/s00296-017-3906-z.

19. Koh YG, Choi YJ, Kwon SK, Kim YS, Yeo JE.
Clinical results and second-look arthroscopic findings after treatment with adipose-derived stem cells for knee osteoarthritis. Knee Surg Sports Traumatol Arthrosc. 2015;23(5):1308-16. doi: 10.1007/s00167013-2807-2.

20. Malanga GA, Dona S, Borg-Stein J, Auriemma M, Singh JR. Refractory Knee Osteoarthritis: AdiposeDerived Stromal Cells Versus Bone Marrow Aspiration Concentrate. PM R. 2018;10(5):524-532. doi: 10.1016/j.pmrj.2018.03.021.

21. Xing D, Wang Q, Yang Z, Hou Y, Zhang W, Chen $\mathrm{Y}$, et al. Mesenchymal stem cells injections for knee osteoarthritis: a systematic overview. Rheumatol Int. 2017. doi: 10.1007/s00296-017-3906-z.

22. Koh YG, Jo SB, Kwon OR, Suh DS, Lee SW, Park SH, et al. Mesenchymal stem cell injections improve symptoms of knee osteoarthritis. Arthroscopy. 2013;29(4):748-55. doi: 10.1016/j. arthro.2012.11.017.

23. Reichenbach S, Rutjes AW, Nüesch E, Trelle S, Jüni P. Joint lavage for osteoarthritis of the knee. Cochrane Database Syst Rev. 2010;(5):CD007320. doi: 10.1002/14651858.CD007320.pub2.

24. Galieva LR, Mukhamedshina YO, Arkhipova SS, Rizvanov AA. Human Umbilical Cord Blood Cell Transplantation in Neuroregenerative Strategies. Front Pharmacol. 2017;8:628. doi: 10.3389/ fphar.2017.00628.

25. Perdisa F, Gostyńska N, Roffi A, Filardo G, Marcacci M, Kon E. Adipose-Derived Mesenchymal Stem Cells for the Treatment of Articular Cartilage: A Systematic Review on Preclinical and Clinical Evidence. Stem Cells Int. 2015;2015:597652. doi: $10.1155 / 2015 / 597652$.

26. Snell DL, Siegert RJ, Surgenor LJ, Dunn JA, Hooper GJ. Evaluating quality of life outcomes following joint replacement: psychometric evaluation of a short form of the WHOQOL-Bref. Qual Life Res. 2016;25(1):51-61. doi: 10.1007/s11136-015-1044-1.

27. Vega A, Martín-Ferrero MA, Del Canto F, Alberca M, García V, Munar A, et al. Treatment of Knee Osteoarthritis With Allogeneic Bone Marrow Mesenchymal Stem Cells: A Randomized Controlled Trial. Transplantation. 2015;99(8):1681-90. doi: 10.1097/TP.0000000000000678. 